\title{
DOS PARQUES INFANTIS À EDUCAÇÃO INFANTIL À BRASILEIRA: O QUE A SEMANA DE 22 TEM A VER COM ISSO? CULTURAS INFANTIS, PEDAGOGIAS DESCOLONIZADORAS E POLÍTICAS PÚBLICAS
}

D https://orcid.org/0000-0002-1886-3790 Ana Lúcia Goulart de Faria ${ }^{\mathrm{A}}$ (D) https://orcid.org/0000-0002-1407-783X Adriana Alves Silva ${ }^{\text {B }}$

\author{
${ }^{\text {A }}$ Universidade Federal de Campinas (Unicamp), Campinas, SP, Brasil \\ ${ }^{\text {B }}$ Universidade Estadual de Santa Catarina (UDESC), Florianópolis, SC, Brasil
}

Recebido em: 20 dez. 2021 | Aceito em: 10 fev. 2022 Correspondência: Adriana A. Silva (adriana.silva@udesc.br)

\begin{abstract}
Resumo
A presente entrevista Dos Parques Infantis à Educação Infantil à brasileira: o que a Semana de 22 tem a ver com isso? (culturas infantis, pedagogias descolonizadoras e políticas públicas), realizada em meados de dezembro de 2021, com a Professora Dra. Ana Lúcia Goulart de Faria, compõe o dossiê Por uma Pedagogia Macunaímica: Infâncias, Estudos Decoloniais e Resistências Plurais na Contemporaneidade, contribuindo nas conexões de eventos e episódios ligados ao movimento modernista que ainda ressoam nas nossas invenções e transgressões no campo da educação, da cultura e da política. Destacando o Manifesto Antropofágico de 1929 e a publicação do Macunaíma de 1928, ao Parque infantil de 1935, realizações posteriores à Semana de 22, mas que fortemente contribuíram para a Educação Infantil à brasileira
\end{abstract}

Palavras-chave: Parques Infantis paulistanos; Mário de Andrade; Pedagogia Macunaímica; Educação Infantil; Pedagogia e Política Pública.

A entrevista aqui apresentada, realizada com a Professora Dra. Ana Lúcia Goulart de Faria, compõe o dossiê Por uma Pedagogia Macunaímica: Infâncias, Estudos Decoloniais e Resistências Plurais na Contemporaneidade, que, inspirado na alegria como nossa força maior, propõe homenagear o centenário da Semana de Arte Moderna, realizada em São Paulo, no período de 13 a 18 de fevereiro de 1922. Aposta na complexidade inventiva e aglutinadora da temática, oportunizando um espaço-tempo fundamental para aprofundarmos a questão de uma Pedagogia Macunaímica, nomeada desta forma por Ana Lúcia desde seu doutoramento , coordenadora do Grupo de Estudos e Pesquisa em Educação e Diferenciação Sócio- Cultural- GEPEDISC linha culturas infantis, que, em 2021, comemora 25 anos de estudos e pesquisas na FE/Unicamp. Uma Pedagogia Macunaímica, numa perspectiva "antropofágica", nos provoca o desafio de pensar uma Educação Infantil que não aparta ciência e arte, educar e cuidar, pensar e fazer, criar e reinventar, pedagogia e política, procurando 
pensar/problematizar, na interlocução com alguns/algumas dos/das artistas e intelectuais modernistas como Mário de Andrade, Oswald de Andrade, Tarsila do Amaral, dentre outr@s, com divergências, rupturas, transgressões múltiplas que apontam o caráter inacabado da experiência da semana de Arte Moderna. Movimento radical que, perscrutando e reconstruindo as suas possibilidades utópicas e germinativas um século após sua realização, sobretudo com a emergência do pensamento decolonial por toda a América Latina, ressoa ainda potente entre nós, que buscamos pedagogias desconolizadoras, a questão: Tupi or not Tupi that is the question.

Ana Lúcia Goulart de Faria é criancista, criançóloga, antifascista, marxista, feminista. Paulistana desvairada, pedagoga, professora permanente colaboradora aposentada da Faculdade de Educação da Unicamp; coordenadora da linha Culturas Infantis do Gepedisc; membro do grupo gestor do Fórum Paulista de Educação Infantil; ex-membro do Conselho Municipal de Educação de Campinas. Atua nas áreas de Pedagogia e Formação Docente, quase exclusivamente na primeira etapa da Educação Básica, na Educação Infantil, em creches e préescolas, na Pedagogia da Infância, com abordagem nas Ciências Sociais, com destaque para a pequena infância e relações de gênero, classe social, relações étnico-raciais, parque infantil, Sociologia da infância, culturas infantis. Foi membro do Colegiado Docente de Doutorado da Università degli Studi di Milano-Bicocca (2010-2018), e por duas vezes foi coordenadora do GT 07 - Educação das crianças de 0-6 anos da ANPED. Desenvolve atualmente três projetos de pesquisa, sempre na intersecção de idade, gênero, classe social, relações étnico-raciais no Brasil, na Itália (com a Università degli Studi Milano Bicocca) e na Suécia (em creche/préescola da rede pública).

Com um roteiro previamente elaborado, a entrevista foi realizada por vídeo chamada, de forma on-line, em dezembro de 2021, por Adriana A. Silva, contando com a colaboração de outras pesquisadoras do Gepedisc Culturas Infantis, que estão no processo de celebração dos 25 anos do grupo, realizado em lives durante o segundo semestre de 2021, disponíveis no canal do youtube. Em especial, destacamos a contribuição das pesquisadoras Marcia Gobbi e Roberta de Paula, que estiveram no $3^{\circ}$ encontro: Furiosas do luto à luta, realizado no dia 26 de novembro de $2021^{\mathrm{i}}$.

Figura 1 - Mario de Andrade, Parque Infantil, São Paulo. 


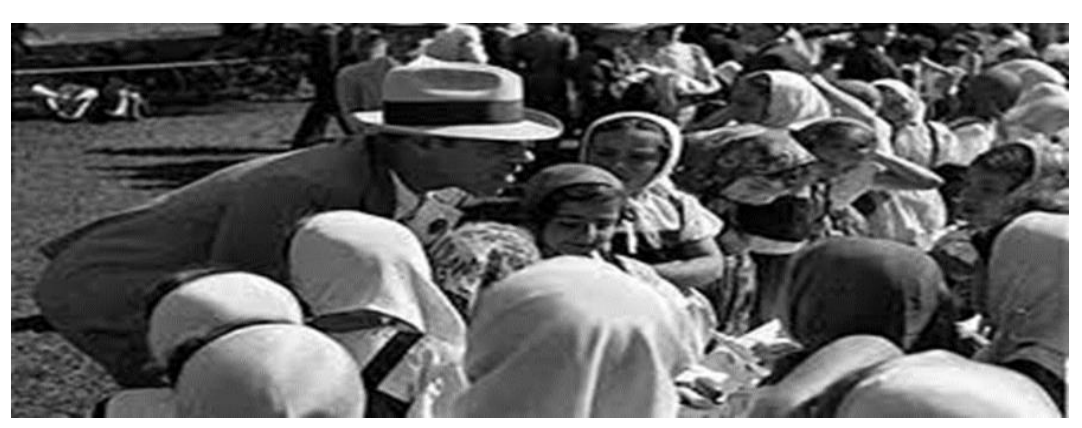

Fonte: ?

Adriana: Ana Lúcia, a foto inserida acima já se tornou quase um clássico, quando queremos nos referir ao Mário de Andrade. Práticas pedagógicas com as crianças e, claro, as propostas contidas na realização dos Parques Infantis que, em muito, encontram-se traduzidas nesse ato do Mário ao se abaixar dirigindo-se às crianças. Você, grande estudiosa dos Parques Infantis, popularizou esta imagem e a discutiu em vários momentos em que tivemos o prazer de ouvi-la. Você poderia, em breves palavras, comentar essa imagem, relacionando-a aos Parques Infantis e uma proposta nomeada por você de Pedagogia Macunaímica?

Ana Lúcia: Acho bem interessante essa pergunta, principalmente vindo de uma estudiosa dos modernistas e do Mário de Andrade. A Márcia Gobbii ${ }^{\mathrm{ii}}$ estudou os desenhos que Mário de Andrade colecionava, e ela estudou os quarenta desenhos, dos mais de mil que estão no Instituto de Estudos Brasileiros (IEB); ela estudou esses quarenta que foram feitos por crianças com idade inferior a frequentar o Parque Infantil. O Parque Infantil era de 3 a 12 anos e os irmãozinhos de 2 anos podiam ir também, irmãozinhos e irmãzinhas. E ele colecionou dos Parques Infantis, da Biblioteca Mário de Andrade, que se chama hoje Mário de Andrade, no centro de São Paulo, na Avenida São Luís; ela estudou esses quarenta, que foram desenhos que ele ganhou das próprias crianças. Quando ele estava num restaurante com uma criança e ela desenhou atrás do ticket, por exemplo, e esse estudo da Márcia foi o doutorado dela, e ela tem um estudo dos modernistas dizendo que as crianças são inventivas. Eu fui orientadora da Márcia. A capa do doutorado, não a capa do livro ${ }^{i i i}$, no livro é uma outra foto, é o Mário de Andrade sentado numa rede com uma criança no colo, mas essa aqui foi a capa que eu usei em minha tese de doutorado (1994), que eu fiz na USP, com a professora Tizuko Kishimoto. A Tizuko foi uma das primeiras que, estudando todas as experiências de Educação Infantil no estado de São Paulo, no mestrado, encontrou os Parques Infantis, assim como várias outras creches e préescolas. E durante o meu doutorado, eu organizei a sua biblioteca e o arquivo. Encontrei muito material que ela tinha coletado acerca dos Parques Infantis e não tinha trabalhado, e fui atrás das fontes que eram, inclusive, a própria Faculdade de Administração da USP, onde tinha muita 
coisa de administração pública, da Prefeitura de São Paulo na gestão do Fábio Prado, quando o Parque Infantil é criado no Departamento de Cultura. Essa foto traz duas questões para a Pedagogia da Educação Infantil, que eu considero bem importantes e gostaria de destacar aqui. Uma é a pedagogia na altura da criança. Esse adulto que não fala lá do alto, olhando para baixo, mas que fala olho no olho com as crianças. Assim como a gente vê nessas fotos que estou colocando aqui na entrevista, da Irene Balaguer, falecida recentemente, em dezembro de 2019, acho que vai fazer dois anos - foi Secretária de Educação de Barcelona e coordenadora, durante anos, do Instituto Rosa Sensat, de Barcelona. A proposta de Educação Infantil de Barcelona é exemplar, muito interessante e na altura da criança, com ela agachadinha, de cócoras, olhando olho no olho da criança.

Figura 2 - Irene Balaguer, Barcelona

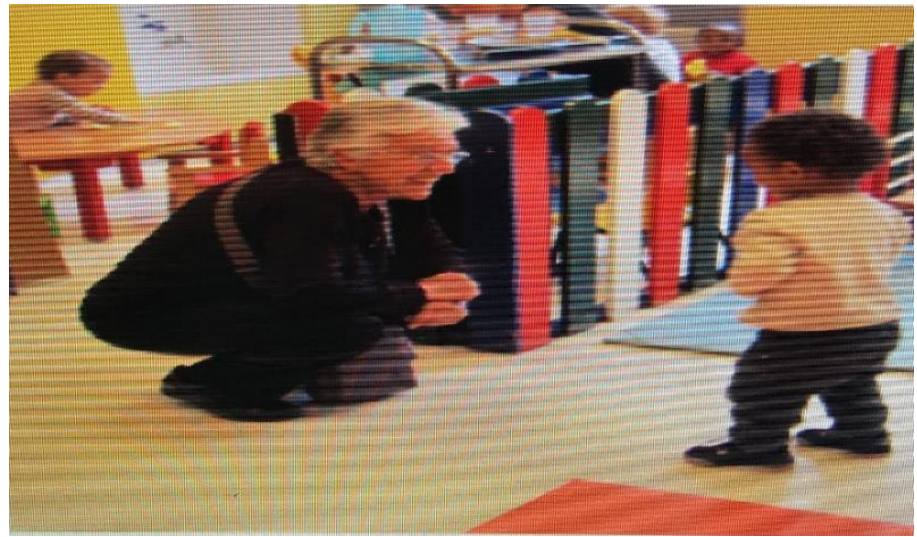

Fonte:?

Figura 3 - Loris Malaguzzi, Itália.

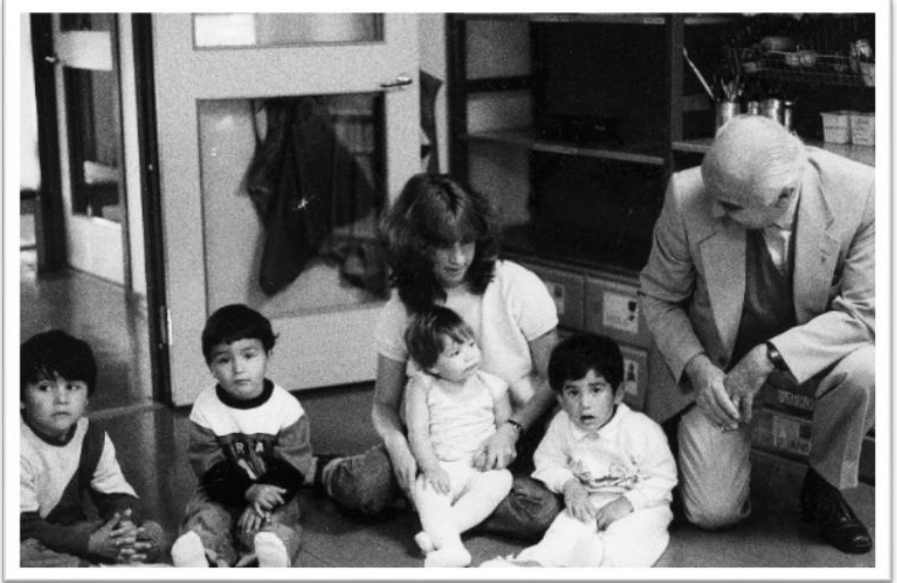

Fonte:?

E o italiano Loris Malaguzzi, que foi professor primário, Secretário da Educação da cidade da Reggio Emiliaiv ${ }^{\text {iv }}$ e que também cria uma proposta que, na verdade, não é nacional, 
porque não é possível pensar, de acordo com Susanna Mantovani e Anna Bondioliv , em uma proposta nacional de 0 a 3 anos. Temos uma proposta de pré-escola nacional, inspirada nas cidades do norte da Itália, nos anos 70-80, quando o partido comunista governava quase todas elas. Loris Malaguzzi, que era Secretário da Educação, está vestido de terno, inclusive, de roupa de secretário da educação; mas ele, quando vai encontrar as crianças, também fica na altura delas. Eu queria destacar essa pedagogia na altura da criança. A pessoa adulta não perde o seu papel nessa relação, mas, com essa postura, cria-se um exercício de horizontalidade a ponto, por exemplo, da gente poder usar uma frase do próprio Malaguzzi, quando ele diz: "vamos seguir as crianças e não os planos". Essa era uma proposta municipal que ele tinha para Reggio Emilia, e que passa a fazer parte de algumas propostas de outros municípios também. Essa relação é mais profunda, nessa horizontalidade você também vai permitir a construção de uma autonomia da criança e não uma tutela do adulto sobre a criança. Estou falando dessa autonomia com A maiúsculo. Uma frase que é de Maria Montessori, mas que Malaguzzi usa bastante, e que a criança fala é: “me ajude a fazer sozinho, sozinha”. É uma construção de autonomia muito especial. Uma consciência de que ser autônomo não significa fazer sem o adulto ou sem outras crianças. O conceito de "cultura infantil" é usado desde os anos 40, no Brasil, e foi formulado por Florestan Fernandes, quando fez uma pesquisa observando as crianças entre elas e os "grupos infantis", como ele chamava. ${ }^{\mathrm{vi}}$

Esse nosso olhar sociológico, inclusive antropológico e das Ciências Políticas, essa nossa abordagem nas Ciências Sociais é que permite verificar essa relação entre adulto e criança, sem ser uma relação de tutela, sem ser uma relação apenas do desenvolvimento infantil. Podemos até retirar a palavra "apenas". Para dizer que não se trata de olhar a criança sozinha, mas essa postura do adulto que fica na altura da criança, ela não está conversando com uma criança só, ela está construindo, permitindo a construção de um pertencimento a partir do qual a criança se constrói como autônoma. É olhando, tendo a sua opinião, e sendo olhada, observada.

Recentemente, em maio de 2021, na edição híbrida do Festival di Teatro per la prima infanzia, em Bolonha, Marina Manferrari ${ }^{\text {vii }}$, trazendo uma discussão acerca da relação da pessoa adulta com as crianças pequenininhas, salientou que ficar na altura das crianças não é abaixar, é ficar na ponta dos pés com muita delicadeza para ver se consegue chegar à altura delas. Segundo Marina:

A propósito das várias alturas para nos posicionar e entrar em relação com as crianças, não posso deixar de pensar na maravilhosa reflexão de Janus Korczak. È muito famosa e seguramente vocês a conhecem, mas me agrada deixá-la aqui para encerrar minha fala. 'Vocês dizem: é trabalhoso estar com as crianças. Vocês têm razão. Depois acrescentam: pois precisamos nos 
colocar no seu nível e abaixar, inclinar, curvar-se, fazer-se pequeno. Vocês agora estão errados. Não é isso que mais cansa. É principalmente o fato de sermos obrigadas a subir até a altura dos seus sentimentos. Esticarmos, alongarmos, levantarmos na ponta dos pés para não magoá-las'.

Adriana: Pode continuar?

Ana Lúcia: Tem um outro, são dois aspectos. Do Mário, que alinha com a Irene e com "ficar na altura", e na foto do Mário, eu queria destacar também uma outra coisa, que é a proposta da instituição de educação das crianças de 3 a 6 anos, uma proposta da instituição educativa, sem sala de aula, os parques infantis.

Adriana: Sim.

Ana Lúcia: Eu posso compartilhar a planta arquitetônica do Parque Infantil, que consta do meu doutorado, e está também em meu livro, para mostrar um espaço enorme, porque era dentro de um bosque. Essa foto abaixo, que é do bairro de Santo Amaro, é o quarto Parque Infantil paulistano, de 1936, dentro de um bosque e tem vários brinquedos: gangorra, balança, tanque de vadiar (que é aquela piscininha rasa com água baixinha que permite mexer os pés para espalhar a água), tanque de areia e tem um espaço bem pequenininho, que é coberto para algumas atividades internas, tais como os banheiros, uma sala da administração e um galpão. Existem várias fotos do Parque Infantil, realizadas pelo fotógrafo José Benedito, que se encontram no arquivo da Profa. Tizuko; por exemplo, as crianças desenhando, porque as que eram do chamado "grupo escolar" iam ao Parque Infantil, no horário contrário da escola. As crianças pequenas, de 3 a 6 anos, conviviam com essas maiores, viam, por exemplo, as crianças sentadinhas, embaixo da árvore, desenhando, fazendo alguma tarefa da escola. Essas crianças, então, estavam vendo, mas não tinham aula, e as crianças da escola também tinham atividades ali. Eu queria chamar a atenção para isso, que, na foto, nessa época, usava-se chapéu. Tanto os homens quanto as mulheres usavam chapéu para passear, para andar na rua, e as crianças, pode notar, as meninas estão aí de lencinho, e os meninos estão de boné, que, aliás, até muito pouco tempo na rede de São Paulo, enquanto teve Parque Infantil, até 1970, mais ou menos - daí é que vai ter as EMEIs -, os meninos usavam boné. A respeito dessa foto, eu acho que a gente pode, em relação a essa questão, terminar.

Figuras 4 - Planta Arquitetônica do Parque Infantil de Santo Amaro, São Paulo. 


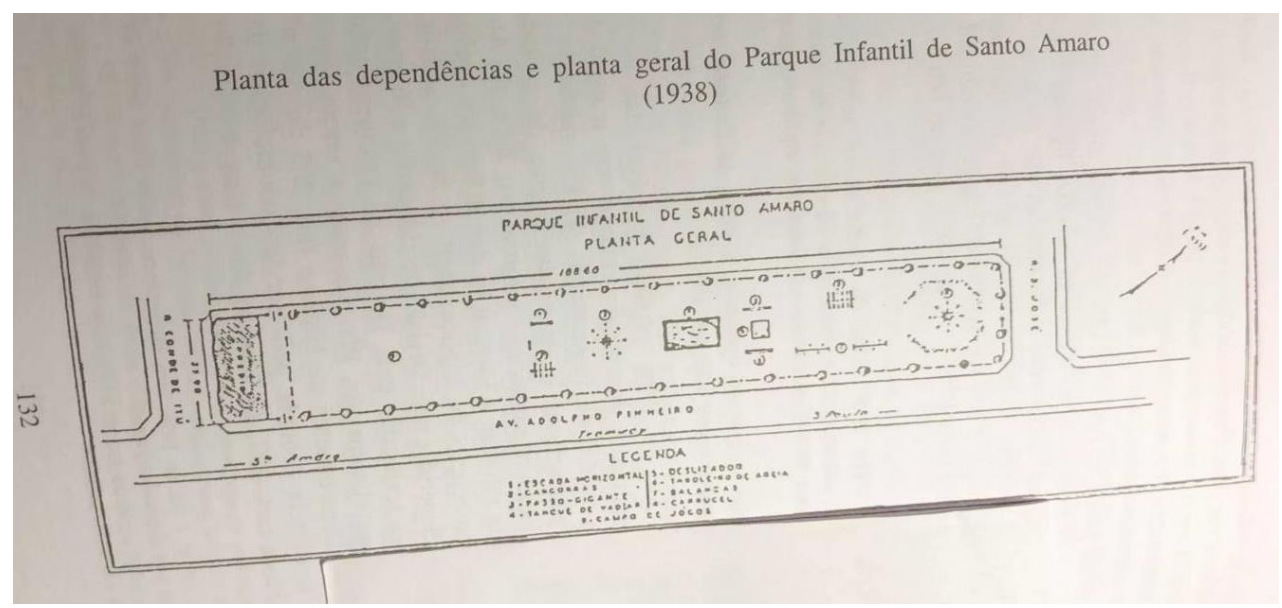

Fonte: Nicanor Miranda. O significado de um parque infantil em Santo Amaro. Departamento de Cultura. 1938

Figuras 5 - Planta Arquitetônica do Parque Infantil de Santo Amaro, São Paulo

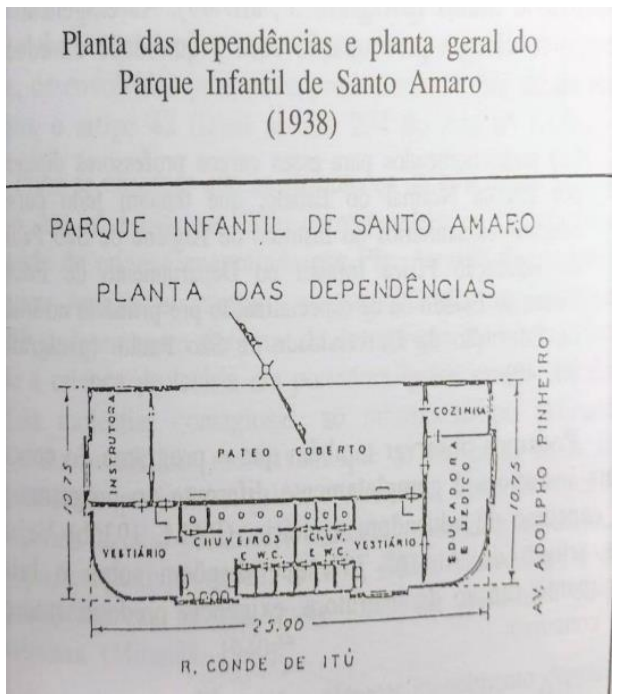

Fonte: Nicanor Miranda. O significado de um parque infantil em Santo Amaro. Departamento de Cultura. 1938

Adriana: Ana, muito obrigada, muito bom. Daí, continuando, essas próximas questões trazem também essa relação. Eu queria que você contasse um pouco a respeito da sua trajetória como pedagoga, pesquisadora, criancista, criançóloga, e o que te levou a esse encontro com alguns aspectos da obra do Mário de Andrade, especificamente a produção relacionada, como você diz, ao educador das crianças pequenas e as políticas públicas para a infância?

Ana Lúcia: O Mário de Andrade era um professor de música do Conservatório. Eu conheci, inclusive, a pessoa que vai substituí-lo, que era marido de uma prima do meu pai, o 
Ciro Brizola, que era um músico também. Conviveram muitos anos com o Mário de Andrade, e ele que vai ficar no lugar do Mário no Conservatório. Mário era professor e cheio de ideias que a gente tem hoje também. Conforme vamos lendo várias coisas, e nem todas estão na minha tese, é uma bibliografia bem interessante, por exemplo, ele tinha um projeto de culinária brasileira que não foi desenvolvido no período em que estava à frente do Departamento de Cultura.

Adriana: Sim.

Ana Lúcia: Ele era um intelectual, não era só um escritor de literatura; por exemplo, temos o livro Táxi, porque, quando ele pegava táxi, ele escrevia contos pequenos, e a Telê Ancona Lopez publicou o livro ${ }^{\text {viii }}$. A obra do Mário de Andrade foi estudada por várias pessoas. A minha colega, Elisa Kossovitch, que foi orientadora da Roberta (que faz a segunda pergunta mais a frente), estuda as danças dramáticas, e pesquisa tudo o que o Mário de Andrade fez no Brasil todo acerca das danças dramáticas, e a Roberta de Paula estava interessada no corpo e tudo mais. A Elisa Kossovitch, por exemplo, estudou a obra toda e trabalhou com a Semiótica para fazer análises para o seu doutorado fortemente inspirado no poema " $\mathrm{Eu}$ sou trezentos" (afinal sem nenhum carater é com todos: o branco, o indígena e o negro) e publicou o livro Mário de Andrade, Plural, ${ }^{\text {ix }}$ que tem um capítulo acerca da infância. Tem uma frase bem famosa da Gilda de Mello e Souza ${ }^{\mathrm{x}}$, que também é uma intelectual da literatura bem importante, e ela falou: "alguém vai precisar estudar a infância na obra do Mário, ela é muito recorrente". A Elisa parte desse artigo, e vai atrás da infância e trabalha com alguns contos do Mário em que a personagem é criança. Eu trabalhei, tenho um capítulo inteiro e estudei esses contos. A visão que ele tem de criança é muito interessante.

\section{EU SOU TREZENTOS}

Eu sou trezentos, sou trezentos-e-cincoenta,

As sensações renascem de si mesmas sem repouso,

Ôh espelhos, Ôh Pirineus! Ôh caiçaras!

Se um deus morrer, irei no Piauí buscar outro!

Abraço no meu leito as melhores palavras,

E os suspiros que dou são violinos alheios;

Eu piso a terra como quem descobre a furto

Nas esquinas, nos táxis, nas camarinhas seus próprios beijos! 
Eu sou trezentos, sou trezentos-e-cincoenta,

Mas um dia afinal eu toparei comigo...

Tenhamos paciência, andorinhas curtas,

Só o esquecimento é que condena,

E então minha alma servirá de abrigo. ${ }^{\mathrm{xi}}$

Adriana: Sim, muito legal.

Ana Lúcia: Eu me baseei na obra de Elisa, e indo até o IEB, o Instituto de Estudos Brasileiros, a Telê Ancona, coordenadora, me permitiu esse privilégio de mexer numas papeladas e eu achei um manuscrito datilografado, uma aula que o Mário deu na Universidade do Rio de Janeiro, quando ele foi morar no Rio e - bom, não sei, Adriana, aproveito para dizer isso, vamos aproveitar - nunca foram publicadas as coisas que o Mário fez na Universidade do Rio de Janeiro. Ele morou pouco tempo no Rio, ele volta para o estado de São Paulo e morre ${ }^{\text {xii }}$.

Adriana: Mas foi na UERJ, Ana, ou na Federal?

Ana Lúcia: Não existia a UERJ.

Adriana: Ah, é verdade!

Ana Lúcia: Chamava Universidade do Distrito Federal ${ }^{\text {xii }}$ (UDF).... tipo a UnB, Universidade do Brasil, uma coisa assim.

Ana Lúcia: E o Mário tem uma aula preparada em que ele fala da infância ${ }^{\text {xiv }}$. Esse manuscrito datilogafado foi publicado na Revista bilíngue do Instituto Rosa Sensat, de Barcelona $^{\mathrm{xv}}$, organizada pela Irene Balaguer, e que passou a ser bilíngue, português e espanhol. No Brasil, eu faço parte de uma equipe coordenada pela Maria Carmen Barbosa, e nós publicamos essa aula que está datilografada para festejar os 80 anos dos Parques Infantis. Era o próprio Mario que datilografava, aliás, uma curiosidade, a sua máquina de escrever chamavase Manuela e está lá em Araraquara, num museu que tem as coisas dele, porque ele era de lá.

Adriana: Que legal, Ana. Manuela.

Ana Lúcia: Manuela, a máquina de escrever. E tem essa aula acerca do conceito de infância, que é bem interessante. Eu destaco novamente a planta arquitetônica. Não tem sala, as crianças ficam em contato com a natureza. Eu tenho um artigo na revista dos 80 anos do Parque Infantil que a Sonia Larrubia organizou na Revista Magistério ${ }^{x v i}$, da Prefeitura de São Paulo, em que eu falo alguma coisa acerca da relação do Mário com a natureza. As crianças estavam direto ali naquele bosque, entendeu?

Adriana: Sim.

Revista Interinstitucional Artes de Educar. Rio de Janeiro, V.8, N.1 - pág. 223-243 jan-maio de 2022: "Por uma pedagogia macunaímica" - DOI: 10.12957/riae.2022.65769 
Ana Lúcia: Em contato, brincando e, inclusive, quando eu trabalhei na Rede em São Paulo - quando ainda era o governo do avô desse que foi prefeito aí, bolsonarista, que faleceu, o Covas -, o Mário Covas, que tinha sido comunista, lá de Santos, quando ele foi prefeito, ainda indicado pelo governador, porque não tinha eleição em algumas prefeituras, mas eu trabalhei nessa gestão que se fez democrática, governo do estado, o Franco Montoro já tinha ganhado pelo MDB. Era uma proposta democrática para o governo de estado, mas as capitais e as cidades, porto, essas coisas, não tinham ainda eleição para prefeito e é aí, inclusive, que eu vou trabalhar em Piracicaba, uma cidade em que o MDB vai ganhar, que era o partido que juntava o pensamento e as ações contra a ditadura. Eles são criados pela ditadura, quando são extintos todos os partidos da época e criados só a Arena e o MDB, mas, conforme tem o governo de estado, também vão ter os governos municipais democráticos e Piracicaba vai fazer uma experiência. Depois, se for o caso, eu comento com vocês a respeito da experiência democrática de Piracicaba, onde se fez a primeira experiência educacional brasileira, para crianças de 0 a 6 anos, em Secretaria de Educação.

Adriana: Ana, pode comentar. Eu acho que já tem tudo a ver, porque a próxima pergunta trata um pouco dessa questão política mesmo, desse trabalho. E aí é bacana, assim, porque as questões foram elaboradas num coletivo de pesquisadoras ligadas ao grupo e, na sua tese, você traz a questão da carta que você escreve. É bonito, e a Roberta, que elaborou a questão, colocou: "Na carta que você escreveu para Mário em seu livro Educação Pré-Escolar e Cultura, em 9 de outubro de 1993, diz que a tese se inspirou nele e o copiou, assim como ele afirmou ter copiado o Macunaíma ${ }^{x v i i}$. Dialogando com Mário sobre o processo de pesquisa, com o objetivo de atualizar esses diálogos, pergunto: o que diria Mário de Andrade hoje, pensando na repercussão que sua pesquisa acerca dos Parques Infantis teve e ainda tem na área?”. E assim, essa experiência que você traz de Piracicaba e até de outras experiências que fazem uma interlocução com essa visão que ele tinha e que atravessa essas décadas todas, né, Ana? Resiste, né?

Ana Lúcia: Bom, a coincidência, inclusive, dessa pergunta da Roberta, são vários pontos, mas só para engatar, quando eu comecei a falar de Piracicaba e você colocou a pergunta, é que em Piracicaba tinham dois Parques Infantis na Secretaria da Assistência. Criamos o Centro Polivalente de Educação e Cultura (CEPEC), que incorporaria essas duas experiências dos 3 a 6 anos, até porque lá era para além dos 6 anos. Em Piracicaba, a gente vai criar creche e pré-escola em uma etapa, a gente chamava assim, porque tudo se chamava CEPEC; tinha o ônibus urbano do CEPEC, e, copiado do Parque Infantil, a gente tinha também as crianças da 
escola do período da tarde que vinham de manhã ao Parque e vice-versa, que nós chamávamos de "educação complementar". O Parque Infantil de Piracicaba era um lugar enorme, dentro da Secretaria da Assistência, e falavam a mesma coisa que falaram para o Mário de Andrade: "onde já se viu dar um clube de campo para as crianças pobres?”. Falavam isso, tanto no tempo do Mário como lá em Piracicaba. Quando, por exemplo, aqui na Suécia, esse bairro em que eu morava aqui que era mais afastado, o conceito de periferia não é o mesmo que o nosso, ele só era mais afastado, porque estava começando a urbanizar, agora tem vários prédios. Nesses anos que eu moro aqui, entre o meu prédio e onde, mais ou menos, terminava, está tudo construído, tem bonde elétrico agora, só que é o seguinte: todo aquele espaço verde está lá reservado, cheio de coisa para criança brincar, com o dinheiro público. Tem uma parte desse terreno que foi para a especulação imobiliária, compraram, construíram. Por exemplo, aqui tem uma lei que são só cinco andares e resolveram fazer um prédio de trinta andares, conseguiram autorização não sei por que, só para ficar com cara de cidade grande, não sei se deu um ataque neles, não sei. Tem coisa de adulto, tem prédio, tem lugar e tal. Mas o espaço para as crianças está garantido. E, outra coisa, só uma curiosidade, os compromissos com a natureza não são só da Greta ${ }^{\text {xviii }}$. Você acredita que vários prédios, quando estavam construindo e abrem para vender na planta, que é mais barato, você ia procurar e alguns não tinham garagem. Por quê? Uma provocação para as pessoas não comprarem carro, não usarem carro, andar a pé ou de bicicleta. Não tem garagem.

Adriana: Muito bom.

Ana Lúcia: Sabe, são mentalidades. Preservar a natureza, prédios que não têm carro, porque ninguém vai ficar respirando aquelas coisas e tal. Embora, agora, já tem uma lei que, até o ano de dois mil e não sei quanto, todos os carros vão ter que ser elétricos. Quem compra carro elétrico hoje já tem gratuita a bateria, já tem um monte de incentivo, entendeu? Então, conclusão, o projeto de cidade, que era isso que estava acontecendo no governo do Fábio Prado, o projeto de urbanização da cidade de São Paulo tinha espaço para criança, o Parque Infantil. Inclusive em uma cidade do interior, como Piracicaba. Aliás, são várias as cidades que o Mário conta numa passagem e eu cheguei a fazer o levantamento delas: Campinas, que é o Celisa, era um Parque Infantil, que já tem tese, a própria Roberta pesquisou lá; tem em Piracicaba, Ribeirão Preto, São Carlos, Santos e outras. Eram oito cidades que fizeram Parques Infantis inspirados no Mário, inclusive com construções parecidas, com aquela única casinha e, o resto, espaço para brincar. Eu tentei juntar esse aspecto da planta arquitetônica, tentei te responder, depois podemos ver se falta alguma coisa. A outra coisa é o copiar. O Mário de Andrade tinha isso, que ele fala que copiou o Macunaíma, é uma divindade venezuelana, ali na divisa com o Amazonas, 
tem tudo a ver com a cultura amazônica, que não tem a ver com a fronteira do estado brasileiro. Tanto é que hoje a nova etnia, a Vanderlete ${ }^{\mathrm{xix}}$ tem trabalhado isso, a nova etnia que tem, das oitenta etnias locais, oitenta e uma, que é a venezuelana. Estão morando no Brasil, eles migraram, né?

\section{Adriana: Sim.}

Ana Lúcia: Tem mais essa etnia nova, as pessoas venezuelanas. Esse negócio de copiar, ele diz que é assim mesmo. Ele pegou essa ideia e eu falo também que eu copiei umas coisas. Essa carta que a Roberta diz que está no meu livro, está no meu doutorado, que foi uma ideia, sabe de quem? Do Wanderley Geraldi. Quando o Basilio, o marido da Sonia Kramer, defendeu o doutorado na Unicamp, eu fiz uma festinha em casa, o Wanderley foi e eu contei que eu estava fazendo o doutorado. Ele falou: "Por que você não faz uma carta para o Mário, então? Faz uma carta também". Eu fiz e até o agradeço na carta, e o Mário de Andrade, além dos poemas e dos livros (destaco inúmeros contos com criança protagonistas), tem muitas cartas publicadas, seja com conteúdo literário, conversando com novas/os escritoras/es e pesquisadoras/es; por exemplo, dentre tantas ele tem uma conversa com Oneyda Alvarenda, Carlos Drummond de Andrade, Pedro Nava, Murilo Miranda, Fernando Sabino; cartas acerca da administração pública. Ele tem um livro de cartas que é um primor, com forte discussão a respeito da administração pública, intitulado Cartas de trabalho- correspondência com Rodrigo de Mello ${ }^{x x}$

Adriana: Nossa, isso é muito legal, Ana.

Ana Lúcia: Muito legal.

Adriana: Não sabia e, olha, até tem tudo a ver com a outra questão que fala disso. Só puxando, mas pode continuar.

Ana Lúcia: Faça isso. Faça, porque na hora de editar vai ser importante você pôr tudo direitinho.

Adriana: Porque, olha, diz assim: "Em seu livro, Educação Pré-Escolar e Cultura você traz várias questões, colocando que muitas delas ficariam sem respostas. Entretanto, sendo elas ainda bastante atuais, como, por exemplo: 'É possível sair do atraso pela administração pública, isto é, pela República? Quem vai educar as novas gerações para que elas sejam diferentes de nós? Quem vai dar continuidade ao trabalho iniciado por Mário de Andrade?'. Assim, com o acúmulo de seus trabalhos, pesquisas e militâncias nos últimos anos, quais são suas considerações sobre elas hoje?". E essa questão que você fala do livro, essa discussão das políticas públicas, Ana, que você sempre chama muita atenção. Você gostaria de comentar? 
Ana Lúcia: O Parque Infantil fazia parte das políticas públicas que o moderno, inclusive a burguesia ilustrada, como vai ser chamada, o Fábio Prado faz parte dessa burguesia ilustrada, tem até uma tese desse assunto que vai construir o Teatro Municipal. O Fábio Prado faz parte dessa burguesia ilustrada que não era comum. Há essa organização, urbanização da cidade com espaço para criança, o espaço público para criança. Tem um conto maravilhoso do Mário, "Primeiro de Maio"xxii, acerca dos ricos que passeavam no centro e só podiam os ricos, que iam com as suas joias, os seus chapéus, para entregar a sua filha para o próximo namorado, faziam os footings, que era uma coisa de rico de praça, e ele fala: "não, nós temos que ganhar as praças". "Primeiro de Maio," e aí tem a passeata, tem greve. Ele vai fazer essa discussão e por isso essa pergunta que ela faz. Se a República vai dar conta de sair do atraso e vai dar conta... porque, na verdade, o Mário se diz socialista. O Fábio Prado é o contrário. A burguesia ilustrada vai fazer a rex publica, a coisa pública, a República, e vai trazer esse espaço para as crianças. Então discutir o Parque Infantil nessa abordagem que estou fazendo, eu estou mostrando isso, o Parque Infantil como direito à educação, que, aliás, é o título original da tese, direito à infância, que era o direito de não trabalhar, porque as crianças pobres estavam trabalhando.

Adriana: Sim.

Ana Lúcia: E o Parque Infantil é um lugar para não trabalhar, para brincar e para ser atendido e para ter contato. O Mário viajava, pesquisava os ritmos, as músicas, e assim fazia a a formação das professoras.

Adriana: Sim.

Ana Lúcia: A Walburga estudou com a Tizuko. O mestrado da Walburga, eu fui da banca, ela estudou a formação das professoras nos Parques Infantis, como o Mário fazia.

Adriana: Muito bom, Ana, e a questão da política pública?

Ana Lúcia: A questão da política pública é tão importante, porque até hoje, por exemplo, para eles conseguirem criar as EMEIs em São Paulo, Escolas Municipais de Educação Infantil, eles fizeram uma lavagem cerebral na cabeça das professoras para dizer que o Parque Infantil era assistência, não era educação. Quando eu fui assessora na gestão da Marta Suplicy, da exMarta Suplicy democrática, a Sonia Larrubia era coordenadora - quem fazia parte da equipe? A Cristina Pires, que vai fazer mestrado comigo sobre o som das crianças, a Márcia Gobbi, já tinha feito mestrado comigo ou estava fazendo, ainda era professora da rede, porque depois ela sai. Ela vai começar a dar aula em faculdade -, então eu fui convidada para ser assessora. Gostaram demais das coisas que eu trouxe, a pedagogia da escuta, a pedagogia das relações e a pedagogia das diferenças, que foi o que eu aprendi na Itália, na minha bolsa de doutorado- 
sanduíche do CNPQ. Eu trago isso e a experiência que eu vou chamar, no Brasil, de Pedagogia Macunaímica.

Adriana: Sim.

Ana Lúcia: Quero deixar registrado que a pedagogia macunaímica, se a gente quiser festejar como 25 anos, se quiser festejar como Semana de 1922, ela vem do estudo que eu faço dos Parques Infantis, contato com a natureza, relação horizontal com as crianças, e a forma não escolar e não da psicologia de falar da Educação Infantil. Uma coisa, educar e cuidar. Tem uma tese de um professor da USP, colega da Tizuko - esqueci o nome dele também, depois vou ver - que o Parque Infantil, ele analisa como? Educar, assistir e recrear, é o título. Não deixa de ser um educar e cuidar da forma possível, porque isso era chamado de assistência. Essa era a questão, o que não era escola... tem uma coisa que eu me orgulho, que escrevi no doutorado, desculpa falar, é que aquilo que não era escola era chamado de assistência. Quando vou fazer o meu doutorado e pergunto para a Tizuko o que ela achava de eu ir para a Itália, tinha acabado de sair na Revista Newsweek ${ }^{x x i i i}$ que a escola mais bonita do mundo era a escola Diana da Reggio Emilia, as pré-escolas lá da Reggio Emilia. A Tizuko, que lia essa revista, me contou. Entrei em contato com a Fúlvia, pedindo referências na Itália, e ela me emprestou o livro que tinha trazido de um congresso lá, Manual de Educação Infantil ${ }^{x x i v}$. Assim, escolhi uma das autoras, a Susanna Mantovani, e fiz em Milão meu doutorado-sanduíche com bolsa do CNPq (a Francesca Emiliani, da Universidade de Bologna, foi também minha supervisora). Anos depois, a Maria Carmen Barbosa, que vai fazer doutorado comigo, e era consultora da Editora Artes Médicas, encaminha esse livro para a tradução e publicação no Brasil.

Adriana: É porque essa coisa das políticas, é legal o link que você está fazendo, da importância, porque esse processo histórico foi de desvincular da assistência, foi uma construção.

Ana Lúcia: Era isso o que eu estava falando. Tiveram alguns lugares, Adriana, quando eu ia direto na unidade, porque eu encontrava as coordenadoras das Diretorias Regionais de Ensino - DREs. Encontrava toda semana, eu passava um dia, de manhã e de tarde, com elas, coordenadoras de Educação Infantil. Eram como se fossem Secretarias de Educação, porque tinham 13 DREs, você imagina. O tamanho que era São Paulo. Tinham algumas DREs, poucas, duas ou três que não queriam saber de mim.

Adriana: Sim.

Ana Lúcia: Porque não queriam saber desse negócio de Parque Infantil, porque Parque Infantil era assistência. Então elas me davam esse feedback, e eu, nas aulas, ia falando: "Olha, 
estou falando aqui da pedagogia italiana, não é para copiar, mas é um jeito de olhar. Eles não chamam de Sociologia da Infância, mas não é a psicologia pura e não é a pedagogia pura”, que é isso que estou conversando com a Agnese ${ }^{\mathrm{xxv}}$, sabe? Sobre o livro dela.

Adriana: Sim.

Assistência. Não é da educação.

Ana Lúcia: Tudo o que não era escola era assistência e a educação do Parque Infantil é educação, embora não escolar.

Adriana: Isso.

Ana Lúcia: É isto que me orgulho de ter escrito, “embora não escolar, é educação". E foi isso que eu negociei com a Tizuko e assim me apresentei para a Susanna Mantovani: "Por que eu vim aqui? Eu não vou copiar nada”. Eu, da Reggio Emilia, nem sei nada. Tanto é que a Susanna me mandou em todos os lugares, menos na Reggio Emilia, porque a Reggio Emilia buscava recursos também dessas outras formas, de tradução, de assessorias. E ela me mostrou quais prefeituras italianas viviam do dinheiro público. Tinha muito dinheiro para a Educação Infantil.

Adriana: Isso foi em noventa? Em que ano?

Ana Lúcia: Noventa e dois, foi quando eu fui fazer o meu estagio sanduíche. Eu defendi a tese em 1994

\section{Adriana: Sim.}

Ana Lúcia: Em 1992, a partir daí eu tenho essa relação, lá em São Paulo eu estava tentando mostrar para elas isso: “Olha, eu não vou fazer a cabeça de ninguém”. Eu estudei o Parque Infantil com as categorias que os italianos falam de educação, embora não escolar. Eles fazem milhões de pesquisas em creche e pré-escola, só que eles não estão dizendo que não tem giz, que não tem aula. Eles não falam o que não tem, eles falam o que é que tem. Por quê? Porque, na Itália, escola é uma coisa, pré-escola é outra coisa e creche é outra coisa. A luta da creche é uma luta recente, da segunda metade do século XX, dos anos 1960, que é do feminismo e da esquerda. Em todo o Norte da Itália, o Partido Comunista estava nas prefeituras. A escola pública fica pública e gratuita em 1911. A pré-escola sempre foi católica e paga. Em 1968, cai um governo e a pré-escola passa a ser pública, gratuita e laica. Então são lutas diferentes, por direitos diferentes. A creche é o direito à diferença, a escola é o contrário. A escola é o direito de ser igual, e não só para os ricos e não só de quem vai ser educado, mas todo mundo. Tanto é que, diferente do Brasil, em que nós temos escola pública e privada, mas com questões complexas e interseccionais de classe, raça/etnia e gênero que marcam o campo dos direitos 
sociais e das desigualdades, reforçando que até recentemente temos que mobilizar na luta pelo direito à escola pública, que estão querendo tirar de novo, já estão mexendo bastante. Porque a última, agora, é mexer no Fundeb.

Adriana: Sim.

Ana Lúcia: Essa coisa da política está aí e o que eu quero é dar o protagonismo ao Mário de Andrade. Tem um texto do Mário de Andrade, de leitura obrigatória - não sei se o dossiê não pode reproduzir, pedir autorização para a editora Martins Fontes ou para o IEB, onde está publicado esse desabafo do Mário de Andrade, intitulado "O Movimento Modernista"xxvi .

Adriana: Sim.

Ana Lúcia: No mínimo, eu vou destacar uma coisa que é: "vamos marchar com as multidões". É o desabafo, lido e escrito, um pouco antes dele morrer.

Adriana: É, mas só para engatar, Ana. Considerando a Semana de Arte Moderna e já que você falou do Movimento Modernista, com essa referência que eu vou buscar, a última questão que a gente colocou foi, justamente, conectar com as comemorações do centenário da Semana de Arte Moderna no país. Que na semana de 13 a 16 de fevereiro completa cem anos, e aí a ideia do dossiê é também fazer essa conexão entre a sua pesquisa e as pesquisas que vieram depois, a partir do seu trabalho, ou mesmo esse trabalho das Redes de ensino. Esse movimento todo, esse legado, digamos. E daí a pergunta é: Como você avalia a atualidade dos conceitos e do pensamento dos modernistas nas problemáticas atuais que atravessam a sociedade brasileira, tais como negacionismos, racismos, autoritarismos, xenofobias, feminicídios, degradação ambiental, novas opressões contemporâneas? E, por exemplo, o que Mário de Andrade poderia nos dizer hoje sobre essas questões? Quais seriam as possíveis lutas e estratégias que ele estaria a nos convocar? É possível ousar e "transver" a pedagogia macunaímica nesses tempos sombrios?

Ana Lúcia: Como disse aqui antes, no texto "Movimento Modernista", do Mario, ele dá excelentes respostas também para pensar esses nossos dias trágicos que vivemos atualmente, com a pandemia e o pandemônio no poder. Mas tem também um belo livro do já saudoso Alfredo Bosi, A dialética da colonização ${ }^{x x v i i}$, no qual ele faz uma análise muito interessante acerca do Nacionalismo no pensamento dos modernistas, em especial entre o Mario de Andrade e o Oswald de Andrade, e assim podemos também refletir acerca da tragédia contemporânea sem anacronismo:

(...) o nacionalismo estético e crítico de Mário de Andrade e o antropofagismo de Oswald de Andrade. Mario inclinava-se a uma fusão de perícia técnica supranacional com a sondagem de uma psicologia brasileira semiprimitiva,

Revista Interinstitucional Artes de Educar. Rio de Janeiro, V.8, N.1 - pág. 223-243 jan-maio de 2022: “Por uma pedagogia macunaímica” - DOI: 10.12957/riae.2022.65769 
mestiça, fluida, romântica. Oswald pregava uma incorporação violenta e indiscriminada dos conteúdos e das formas internacionais pelo processo antropofágico brasileiro, que tudo devoraria e tudo fundiria no seu organismo inconsciente, entre anárquico e matriarcal. Ambas as teses, apesar de tão distintas na sua formulação, podem avizinhar-se enquanto postulam uma assimilação de códigos europeus por um presumido caráter (ou nao-carater) nacional brasileiro, que se explicaria por uma combinação de mentalidade pré-lógica (a expressão era tomada a Levy-Bruhl) e formas civilizadas sobrepostas por motivos históricos: colonização, catequese etc. Os modos pelos quais essas hipóteses (em que a Antropologia ainda se entregava a uma discutível psicologia dos povos) serviram as obras literárias do modernismo devem ser objeto da análise, da interpretação e da história da poesia e da prosa brasileira coetâneas. Para o fio de nosso discurso, importa sublinhar que o modernismo, especialmente na sua versão paulista ou concentrada em São Paulo, trabalhou a relação entre cultura erudita e cultura popular segundo um vetor decididamente mitopoético. Cultura popular e entendida pelo autor de Macunaíma e pelo autor do Manifesto Antropofágico, em primeiro lugar, como expressão da sensibilidade tupi, articulada em lendas, mitos e ritos recontados pelos cronistas, pelos jesuítas e por alguns antropólogos contemporâneos. Em um segundo tempo, um estudioso infatigável como Mario de Andrade se pôs a pesquisar também o mundo do negro e do mestiço, já então como folclorista quase profissional; mas já não era o momento heroico das definições modernistas fundamentalmente primitivistas. A exploração do Brasil pobre moderno seria obra dos romancistas regionalistas, particularmente os nordestinos e os gaúchos que constituem a nossa melhor tradição neo-realista. De São Paulo, região industrial, capitalista, ponta-delança da modernização cultural, saiu a flecha do primitivismo radical, como se a alternativa real fosse a expressa no famoso trocadilho oswaldiano: "tupy or not tupy, that is the question". Mas essa alternativa era, apenas, uma alternativa estética do modernismo da década de 20: primitivismo puro ou futurismo, eis a questão desse modernismo. Deve, provavelmente, haver uma relação estrutural entre momentos históricos ultra modernizantes e programas estéticos irracionalistas ou, como se prefere dizer hoje, contraculturas.

Adriana: Sim.

Ana Lúcia: Infelizmente, a gente não quer ficar falando, mas é bom que a gente lembre mesmo. Na verdade, essas perguntas específicas referentes ao momento atual, eu acho que elas poderiam vir assim, como esse manifesto feito naquela época poderia fazer uma interlocução com o que nós estamos vivendo hoje, com os intelectuais de hoje, alguma coisa assim. Mas volta naquelas outras perguntas, aquelas quatro outras perguntas da Roberta. Como é que era? O que se pode fazer para sair do atraso, é uma proposta socialista, e depois, como é que eram as outras perguntas? Achou aí?

Adriana: É, não, aqui, a primeira fala um pouco desse educador das crianças pequenas. A segunda, o que diria Mário de Andrade hoje, pensando na repercussão que a sua pesquisa a respeito dos Parques Infantis teve e ainda tem na área? É possível sair do atraso pela administração pública, isto é, pela República? Quem vai educar as novas gerações para que elas sejam diferentes de nós? Quem vai dar continuidade ao trabalho iniciado por Mário? 
Ana Lúcia: Isso eu posso responder. Por exemplo, esse daí das novas gerações, a gente pode falar da Píppi Meialonga? Você tem uma escritora sueca traduzida no Brasil que é contra o adultocentrismo.

\section{Adriana: Sim.}

Ana Lúcia: A relação horizontal do agachado é antiadultocêntrica. O que não quer dizer que a pessoa adulta não tenha nenhum papel; dá para puxar o fio por aí e dar até o exemplo da Píppi Meialonga. Essa é uma coisa que eu queria falar. A outra coisa, quem é que vai... e para isso aquela frase da Astrid Lindgren ${ }^{\text {xxviii }}$, autora sueca da Pippi, quando ela diz: "só façam o que as pessoas adultas pedirem se elas justificarem porque estão ordenando", e, com isso, você está educando as crianças rebeldes e questionadoras e chama as crianças a problematizarem e discordarem. O Mário educador, que era professor do Conservatório de música e que fazia a formação das professoras do Parque Infantil, que, para nós, é o papel mesmo de um educador. Qual era a outra? Repete as quatro.

Adriana: É... quem vai dar continuidade ao trabalho iniciado...

Ana Lúcia: O trabalho iniciado por ele, quando a Maria José, por exemplo, foi trabalhar na Emei que tinha sido parque infantil em Campinas, no Celisa Cardoso do Amaral. Foi uma ideia de achar coisas do passado, fazer as "garimpagens". Olhar as coisas, como o Eduardo falou na aula sobre o pensamento da Hannah Arendt, de você buscar no passado pesquisas a respeito de parques infantis. Tem uma dissertação de mestrado em Campinas, que o Moysés Kuhlmann Jr. orientou ${ }^{x x i x}$. Eu orientei um TCC analisando as fotografias da época referentes aos espaços do ex-parque infantil, hoje Emei Celisa (pela Fernanda Tonolli). E o TCC da Roberta de Paula, que fez a pesquisa das fotos dos/as pequeninhos/as. Esses Parques Infantis, como no caso de Piracicaba, influenciaram as políticas públicas, a relação com a natureza, os espaços sem sala de aula, espaços grandes para brincar. Não é escola e não é assistência propriamente dita e, no entanto, o educar e o cuidar é indissociável. A dissertação de Carolina Filizola realizada na USP ao contrário, problematiza os parques infantis chamando a atenção para a reprodução e suas contradições. À moda antropofágica, como assim chamou o professor belga Michel Vandenbrouck, quando estando no Brasil em 2012, conheceu nossas origens.

Pois o que encontrei nessa viagem ao Brasil foi justamente o contrário. Foram questões lentas. Será que posso ser quem sou? Como nós faremos para viver juntos, nos coletivos? E, na verdade, de que servem os locais destinados à primeira infância?

Ali encontrei principalmente uma criatividade extraordinária para trabalhar com esse discurso dominante de evidence-base education, para enfrentar o 
domínio da literatura de língua inglesa nesse campo. Trata-se de uma maneira antropofágica (Tupi or not Tupi), que incorpora esses discursos, que os come, que os digere para deles fazer alguma coisa, outra coisa.

$\mathrm{Na}$ realidade, essa atitude antropofágica se conjuga perfeitamente com o respeito pela diversidade. Pois negar os antecedentes de uma criança seria the fazer mal, causar-lhe dano. Porém, reduzi-la a suas origens também lhe faria mal. Respeitar a criança e sua família significa respeitar suas identidades, no plural: suas identidades nômades, múltiplas e, portanto, antropofágicas. ${ }^{\mathrm{xxx}}$

Adriana: Acho que está bom, Ana. Por fim, somente queria incluir uma proposição da genialidade do Mario de Andrade com o personagem Macunaima, nosso herói nacional sem nenhum caráter, que eternizou a resistência à exploração colonial com o "Ai que Preguiça", do Macunaíma, e que pudéssemos finalizar com a Divina Preguiça.

Mil vezes não! Forçoso é continuar, para que o idealismo floresça e as ilusões fecundem, a castigar os que se aviltam no "far niente" burguês e vicioso e a exalçar os que compreenderam e sublimaram as artes, no convívio da divina Preguiça! $!^{x x x i}$

\section{Referências}

ANDRADE, Mário de. $6^{\mathrm{a}}$ aula. O primitivo- a criança. In: Depoimentos-2, Centro de Estudos Brasileiros, 1966.

ANDRADE, Mário. Divina Preguiça. Publicado no jornal A Gazeta, São Paulo, 03/09/1918, Ano XIII - num. 3790.

ANDRADE, Mário de. Contos Novos. Rio de Janeiro: Nova Fronteira, 2015.

ANDRADE, Mário de. Cartas de trabalho- correspondência com Rodrigo de Mello. Brasília: Ministério da Educação e Cultura, Secretaria do Patrimônio Histórico e Artístico Nacional, Fundação Pró-Memória, 1981. n.33.

ANDRADE, Mário. O movimento modernista. In: Aspectos da literatura brasileira. 5.ed. São Paulo: Martins, 1974.

BONDIOLI, Anna; MANTOVANI, Susanna (org). Manual de Educação Infantil. Porto Alegre: Artes Médicas, 1998.

BOSI, Alfredo. Dialética da colonização. 2. ed. São Paulo: Companhia das Letras, 1992.

BUARQUE DE HOLLANDA, Heloisa. Macunaíma da literatura ao cinema. RJ: José Olympio, 1978.

CASTRO, Moacir Werneck de. Mario de Andrade: exílio no Rio. São Paulo: Rocco, 2015. 
FARIA, Ana Lúcia Goulart de. e SILVA, Adriana A. Loris Malaguzzi-Por uma nova cultura da infância. Revista Educação,Cultura e Sociologia da Infância. SP:Editora Segmento.número especial: A criança em foco. p. 98-111, 2013.

FARIA, Ana Lúcia Goulart de. El niño es artista? Mario de Andrade (1893-1945).

Infância Latinoamericana,seção História da Educação. Barcelona: n.14 Derechos Culturales pag 40-51 agosto de 2015 .

FARIA, Ana Lúcia Goulart de. Carta a Mario de Andrade-80 anos dos Parques Infantis. Revista Magistério, Edição Especial, Prefeitura Municipal de São Paulo: n.2, p.6-9, 2015.

FARIA, Ana Lúcia Goulart de. Educação Pré-Escolar e Cultura. Para Uma Pedagogia da Educação Infantil. São Paulo: Cortez, 2001.

FERNANDES, Florestan. Trocinhas do Bom Retiro. In: FERNANDES, Florestan. Folclore e mudança social na cidade de São Paulo. São Paulo: Martins Fontes, 2004.

GOBBI, Marcia Aparecida. Desenhos de outrora, desenhos de agora: Mário de Andrade colecionador de desenhos e desenhistas. São Paulo: Ed. Annablume, 2011.

KOSSOVICH, Elisa. Mário de Andrade, Plural. Campinas: Editora da Unicamp, 1993.

LINDGREN, Astrid. Pippi meia longa. SP: Companhia das Letrinhas, 2016.

LOPEZ, Telê Ancona (org) Mário de Andrade- Táxi e crônicas no Diário Nacional. São Paulo: Duas Cidades, 1976.

MANFERRARI, Marina. Festival di Teatro per la prima infanzia. Bologna: 2021.

MIRANDA, Nicanor. O significado de um parque infantil em Santo Amaro. Departamento de Cultura.Divisão de Ensino e Recreio. Prefeitura Municipal de São Paulo, 1938.

RAMOS, Maria Marta Silvestre. História da Educação infantil Pública Municipal 19401990. Tese de doutorado. Universidade de São Francisco. São Paulo.

SOUZA, Gilda de Mello e. Mário de Andrade- Exílio da preguiça elevada. Revista Banas, 1023 nov, p. 33-38, 1975.

Revista Newsweek, 1991.

VANDENBROECK, Michel. Prólogo. In: VANDENBROECK, Michel; ABRAMOWICZ, Anete. Educação infantil e diferença. Campinas: Papirus, 2013.

\footnotetext{
i Disponível no canal do Gepedisc Culturas Infantis no Youtube. https://www.youtube.com/watch?v=MqmYBkXFcMw\&t=4531s Acesso em: 18 dez. 2021.

ii GOBBI, Marcia A. Desenhos de outrora, desenhos de agora: Mário de Andrade colecionador de desenhos e desenhistas. São Paulo: Ed. Annablume, 2011
} 
iii FARIA, Ana Lúcia Goulart de. Educação Pré-Escolar e Cultura. Para Uma Pedagogia da Educação Infantil. São Paulo: Cortez, 2001.

iv FARIA, Ana Lúcia Goulart de. e SILVA, Adriana A. Loris Malaguzzi-Por uma nova cultura da infância. Revista Educação, Cultura e Sociologia da Infância. SP: Editora Segmento; número especial: A criança em foco. p. 98111, 2013.

${ }^{v}$ BONDIOLI, Anna; MANTOVANI,Susanna(org). Manual de Educação Infantil. Porto Alegre: Artes Médicas, 1998.

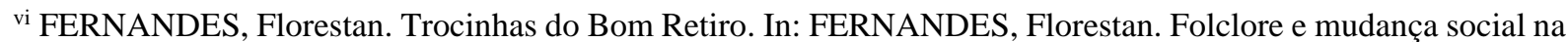
cidade de São Paulo. São Paulo: Martins Fontes, 2004.

vii MANFERRARI, Marina. Festival di Teatro per la prima infazia. Bologna: 2021.

viii LOPEZ, Telê Ancona. Apanhando “Táxi”. In: ANDRADE, Mário de. Táxi e crônicas no Diário Nacional. São Paulo: Duas Cidades, 1976.

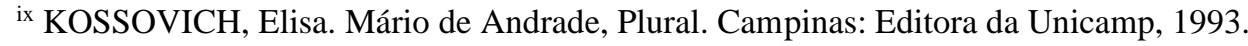

${ }^{x}$ SOUZA, Gilda de Mello e. Mário de Andrade- Exílio da preguiça elevada. Revista Banas, 10-23 nov, 1975.

xi Mario de Andrade apud FARIA, Ana Lúcia Goulart de. Educação Pré-Escolar e Cultura. Para Uma Pedagogia da Educação Infantil. São Paulo: Cortez,2001.

xii CASTRO, Moacir Werneck de. Mario de Andrade: exílio no Rio. São Paulo: Rocco, 2015.

xiii A história da Universidade do Estado do Rio de Janeiro (UERJ) teve início em 4 de dezembro de 1950, com a promulgação da lei municipal $n^{\circ} 547$, que cria a nova Universidade do Distrito Federal (UDF). Diferente da instituição homônima, fundada em 1935 e extinta em 1939, a nova Universidade ganhou força e tornou-se uma referência em ensino superior, pesquisa e extensão na Região Sudeste. Em 1958, a UDF foi rebatizada como Universidade do Rio de Janeiro (URJ). Em 1961, após a transferência do Distrito Federal para a recém-inaugurada Brasília, a URJ passou a se chamar Universidade do Estado da Guanabara (UEG). Finalmente, em 1975, ganhou o nome definitivo de Universidade do Estado do Rio de Janeiro. Fonte: https://www.uerj.br/a-uerj/a-universidade/ ${ }^{\text {xiv }}$ ANDRADE, Mário de. $6^{\mathrm{a}}$ aula. O primitivo- a criança. In: Centro de Estudos Brasileiros. Depoimentos-2, p. 67-76, 1966.

${ }^{x v}$ FARIA, Ana Lúcia Goulart de. El niño es artista? Mario de Andrade (1893-1945) Infancia Latinoamericana. seção História da Educação. Barcelona:n.14 Derechos Culturales,pag. 40-51, 2015.

xvi FARIA, Ana Lúcia Goulart de. Carta a Mario de Andrade-80 anos dos Parques Infantis. Revista Magistério, Edição Especial, Prefeitura Municipal de São Paulo: n.2, p.6-9, 2015.

${ }_{\text {xvii }}$ Copiei, sim. (...) O que me espanta e acho sublime de bondade, é os maldizentes se esquecerem de tudo quanto sabem, restringindo a minha cópia a Koch-Grunberg, quando copiei todos. (...) Confesso que copiei, copiei às vezes textualmente. Quer saber mesmo? Não só copiei os etnógrafos e os textos ameríndios, mais ainda, na "Carta pras Icambiabas", pus frases inteiras de Rui Barbosa, de Mário Barreto, de cronistas portugueses coloniais, e devastei tão preciosa quão solene língua dos colaboradores da "Revista de Língua Portuguesa". (Andrade, 1931, apud, Buarque de Hollanda, Heloisa. Macunaíma da literatura ao cinema. RJ: José Olympio,1978)

xviii Greta Tintin Eleonora Ernman Thunberg é uma jovem ativista ambiental sueca, que iniciou sua militância no Ensino Médio.

xix Vanderlete Pereira da Silva, professora da Universidade do Estado do Amazonas - UEA e pesquisadora do Gepedisc Culturas Infantis.

${ }^{x x}$ ANDRADE, Mário de. Cartas de trabalho- correspondência com Rodrigo de Mello. Brasília: Ministério da Educação e Cultura, Secretaria do Patrimônio Histórico e Artístico Nacional, Fundação Pró-Memória, 1981. n.33.

xxi FARIA, Ana Lúcia Goulart de. Educação Pré-Escolar e Cultura. Para Uma Pedagogia da Educação Infantil. São Paulo: Cortez, 2001.

xxii ANDRADE, Mário de. Contos Novos. Rio de Janeiro: Nova Fronteira, 2015.

xxiii Revista Newsweek, 1991.

xxiv BONDIOLI, Anna; MANTOVANI, Susanna (org). Manual de Educação Infantil. Poá: Artes Médicas, 1998.

${ }^{x x v}$ Agnese Infantino Dipartimento di Filosofia e Scienze dell'Educazione, Università degli Studi di MilanoBicocca (UniMiB).

xxvi ANDRADE, Mário. O movimento modernista. In: Aspectos da literatura brasileira. 5.ed. São Paulo: Martins, 1974.

xxvii BOSI, Alfredo. Dialética da colonização. 2. ed. São Paulo: Companhia das Letras, 1992.

xxviii LINDGREN, Astrid. Pippi meia longa. SP: Companhia das Letrinhas , 2016.,

${ }^{\text {xxix }}$ RAMOS, Maria Marta Silvestre. História da Educação infantil Pública Municipal 1940-1990. Tese de doutorado. São Paulo. Universidade de São Francisco.

xxx VANDENBROECK, Michel. Prólogo. In: VANDENBROECK Michel; ABRAMOWICZ, Anete. Educação infantil e diferença. Campinas: Papirus, 2013.

xxxi ANDRADE, Mário. Divina Preguiça. Publicado no jornal A Gazeta, São Paulo, 03/09/1918, Ano XIII - num. 3790).

Revista Interinstitucional Artes de Educar. Rio de Janeiro, V.8, N.1 - pág. 223-243 jan-maio de 2022: "Por uma pedagogia macunaímica" - DOI: 10.12957/riae.2022.65769 